\title{
Comunicar ciência em Portugal: uma avaliação das perspectivas para 0 estabelecimento de formas de diálogo entre cientistas e o público
}

Ana Godinho Coutinho*, Sofia Jorge Araújo** e Mónica Bettencourt-Dias***

\section{Resumo}

Este artigo avalia as perspectivas para o estabelecimento de formas de comunicação directa e bidireccional (diálogo) entre cientistas e o público, em Portugal, em substituição da comunicação indirecta e unidireccional, actualmente prevalecente. Um maior envolvimento do público com a ciência requer meios de comunicação que promovam o diálogo entre cientistas e o público, permitindo partilhar os valores e o sistema social da ciência. Neste sentido, organizámos e avaliámos uma conferência de fim-de-semana pioneira em Portugal, entre cientistas do Instituto Gulbenkian de Ciência (IGC), um instituto de investigação biomédica, e o público de Oeiras, onde o instituto se localiza. O formato da conferência foi adaptado do modelo dinamarquês das conferências de consenso, que são um meio exemplar para o diálogo. Estiveram envolvidos dois painéis: um painel leigo, constituído por membros do público, e um painel de cientistas, constituído por investigadores do IGC. O painel leigo estabeleceu a agenda da conferência, conduziu as sessões e preparou um relatório de consenso. A avaliação e as consequências desta conferência de fim-de-semana sugerem que o diálogo entre cientistas e o público é possível, viável e que promove maior envolvimento do público com a ciência.

Palavras-chave: comunicação da ciência; workshop, competências comunicativas; media, envolvimento do público

\footnotetext{
* Instituto Gulbenkian de Ciência, Oeiras; Associação Ciência para o Desenvolvimento; Associação Viver a Ciência. E-mail: acoutin@igc.gulbenkian.pt

** Institut de Biología Molecular de Barcelona, Parc Cientific de Barcelona, Espanha; Associação Viver a Ciência.

*** Department of Genetics, University of Cambridge, Reino Unido; Associação Ciência para o Desenvolvimento; Associação Viver a Ciência. E-mail: mbcd2@cam.ac.uk
} 


\section{Introdução}

A ciência e a tecnologia fazem parte integrante das sociedades modernas: o progresso económico e o bem-estar de uma nação dependem do conhecimento adquirido pela ciência e da sua aplicação na tecnologia. Mais ainda, o conhecimento científico é necessário para muitas decisões do dia-a-dia e para uma melhor compreensão do mundo que nos rodeia: desde os medicamentos que tomamos, ao modelo do telemóvel que decidimos comprar. O exercício da cidadania e a eficiência do processo democrático dependem largamente de um melhor conhecimento de temas relacionados com a ciência e a tecnologia, que muitas vezes estão na base de diversas decisões políticas. O efeito de estufa, a utilização de organismos geneticamente modificados, a investigação com células estaminais humanas, as tecnologias de vigilância pública, são exemplos de controvérsias de base científica que têm repercussões na sociedade e que requerem uma maior compreensão por parte do público, para ser possível um debate mais produtivo.

Durante as últimas duas décadas tem-se desenvolvido na Europa um movimento para aumentar a cultura científica dos cidadãos. Têm sido identificados vários actores deste movimento: os governos e as instituições a eles ligadas, a comunidade científica, o sistema educativo (formal e informal), os museus de ciência e os centros de ciência, os media, a indústria e o sector privado (Miller et al., 2002). No Reino Unido, onde este movimento tem sido bem documentado, a publicação do relatório 'The Public Understanding of Science', pela Royal Society, é muitas vezes referido como o marco do início deste processo (Bodmer, 1985). Este relatório, que ficou conhecido como o 'Bodmer Report' (Sir Walter Bodmer foi o coordenador do grupo de trabalho), atribui aos cientistas a responsabilidade de aumentar a cultura científica do público - os cientistas foram incentivados a 'estar disponíveis para comunicar com o público e considerar seu dever fazê-lo’ (Bodmer, 1985: 36).

Desde a publicação do 'Bodmer Report' tem havido um crescimento extraordinário na variedade e quantidade de actividades que fazem a ponte entre a comunidade científica e o público, em toda a Europa (Miller et al., 2002). Todas estas actividades se têm desenrolado sob o título de Compreensão Pública da Ciência ${ }^{1}$; em que por 'compreensão pública' se entenderia não só 'compreensão' dos conceitos, termos e resultados científicos, mas também a percepção e a valorização por parte do público da contribuição que a ciência e a tecnologia fazem para as suas vidas. Estas actividades recorrem aos media (rádio, televisão, jornais, revistas), a seminários e conferências, aos museus e centros de actividades como mediadores da informação (Farmelo, 1997; Miller et al., 2002).

Subjacente a muitas destas actividades está a vontade de aumentar o interesse na ciência e a valorização da ciência pelo público, através do aumento dos seus conhecimentos de ciência. Esta linha de pensamento baseia-se em sondagens europeias que revelam baixo conhecimento de ciência e falta de interesse em assuntos científico-tecnológicos (Miller et al., 2002). Os cientistas envolvidos em actividades de comunicação 
com o público assumem que o problema da falta de interesse pela ciência assenta na existência de um público com parcos conhecimentos científicos, mas com vontade de aprender. O papel desses investigadores seria assim de transmitir uma ciência parcialmente digerida, através dos media, dos livros de divulgação científica, de seminários e museus. Esta visão pedagógica, de 'cima para baixo', foi chamada de 'modelo do défice cognitivo' (deficit model) e a sua eficácia tem sido questionada (Gregory \& Miller, 1998). De facto, as últimas duas sondagens europeias sobre as atitudes do público com a ciência mostram que, apesar do aumento do número de actividades, o nível de conhecimento científico dos europeus aumentou apenas 1,1\% em nove anos (de 56,7\% em 1992 para 57,8\% em 2001) (European Commission, 2001; Miller et al., 2002). Mais ainda, estudos em vários países mostram que a relação entre saber e valorização não é tão simples como muitas vezes se representa e que nem sempre mais conhecimento científico implica mais interesse ou atitudes mais positivas perante a ciência (Ávila \& Castro, 2002; Firmino da Costa et al., 2002; Thomas, 1997; Wynne, 2001).

Em alternativa ao 'modelo do défice cognitivo' desenvolveu-se outra abordagem à promoção da cultura científica, mais reflectiva: o 'modelo interactivo' que incorpora os efeitos do contexto social e dos conhecimentos adquiridos ao longo da vida na forma como o público assimila e utiliza a ciência. Este modelo é baseado em estudos na área das ciências sociais que sugerem que, apesar de o público ter pouco conhecimento dos factos e dos conceitos científicos, possui um conhecimento local, uma compreensão e interesse no assunto - aquilo a que os cientistas sociais chamam de 'conhecimento situado' (situated knowledge) (Irwin, 1995).

Esta abordagem utiliza um novo conceito operacional de ciência, em que a ciência é uma forma de conhecimento que não detém uma verdade absoluta, que pode ser problemática e nem sempre beneficia as populações - muito diferente do conceito de ciência criado pelo 'modelo do défice cognitivo'. Assim, como componente da sociedade, a ciência deve ser pensada e discutida por todos os seus membros. O relatório da Câmara dos Lordes, 'Science and Society' (House of Lords, 2000), discute esta mudança de atitude perante a visão da ciência: 'O conhecimento obtido através da investigação científica não tem em si próprio uma dimensão moral; mas a forma como a investigação é feita e a aplicação do conhecimento colidem inevitavelmente com problemas morais (...). Ao declararem os valores subjacentes ao seu trabalho [os cientistas], e ao empatizarem com os valores e as atitudes do público, mais facilmente conseguirão o seu apoio'. A sigla PUS tem sido substituída pela sigla PEST (Public Engagement with Science and Technology $y^{2}$.

A abordagem reflectiva defende que os cientistas devem estar a par do conhecimento situado do público e adaptar os seus métodos de comunicação de acordo com o contexto em questão. Esta abordagem requer fóruns que possibilitem o diálogo: a comunicação directa e bidireccional entre os cientistas e o público, em que há um

\footnotetext{
${ }^{2}$ Envolvimento Público com a Ciência e a Tecnologia.
} 
feedback imediato entre os dois grupos e em que a visão paternalística e autoritária dos cientistas, e da ciência, é diluída (Thomas, 1997; Farmelo, 1997).

\subsection{Fóruns para o diálogo entre cientistas e o público}

Há hoje em dia um interesse crescente, por parte dos governos e instituições de investigação, em debates para promover um maior envolvimento do público com a ciência. Neste sentido, têm sido criados vários espaços de discussão entre cientistas e o público, principalmente nos países do Norte da Europa onde a participação pública na ciência é mais comum (Hamstra, 1995; Gonçalves, 2002). Estes fóruns de diálogo estão normalmente associados a exercícios de avaliação de tecnologias e incluem scenario workshops, júris de cidadãos (citizen juries), entrevistas de grupo (focus groups), sondagens deliberativas e conferências de consenso (Joss \& Durant, 1995). Estas últimas popularizaram-se na Europa como uma forma de avaliação de novas tecnologias e de participação do público na ciência. Focar-nos-emos nas conferências de consenso, uma vez que foi nestas que nos baseámos para o estudo apresentado neste artigo.

Tal como com outras formas de diálogo, mencionadas acima, a ideia por detrás das conferências de consenso é de alargar o debate, normalmente restrito a peritos e cientistas, ao resto do público. Uma conferência de consenso é assim um inquérito público levado a cabo por um grupo de cidadãos, sobre um tema científico-tecnológico que gera, ou pode vir a gerar, controvérsias sociais (Joss \& Durant, 1995; Grundhal, 1995).

Nos Estados Unidos as conferências de consenso são empregues há mais de 30 anos como uma forma de avaliação de tecnologias aplicadas à medicina, envolvendo apenas peritos médicos (Jorgensen, 1995). Nos anos 80, o Danish Board of Technology, na Dinamarca, adaptou as conferências de consenso substituindo um dos painéis de peritos por um painel leigo, constituído por cidadãos comuns, que não representam nenhum grupo de interesse directo no tema em debate (Klüver, 1995). Na Europa organizaram-se já várias dezenas de conferências de consenso, nomeadamente na Dinamarca, no Reino Unido, na Suíça e na Bélgica. Estas conferências têm abordado vários temas, desde a tecnologia educativa aos testes genéticos e à biotecnologia de plantas (Klüver, 1995; Lee, 1995). Têm como objectivo dar aos políticos e governantes informação sobre o estado-de-arte dos avanços científico-tecnológicos, e ainda facilitar o debate público sobre esses avanços.

As conferências de consenso tornaram-se assim num modelo de democracia participada, mas também num paradigma de diálogo. Numa conferência de consenso, o painel leigo (constituído por 10 a 31 cidadãos) coloca as suas questões a um painel de especialistas, ouve as respostas, interroga os peritos novamente e produz um relatório de consenso que resume as suas preocupações, expectativas e recomendações (Farmelo, 1997; Joss \& Durant, 1995).

\subsection{Sensibilização do público para a ciência em Portugal}

A União Europeia tem feito inquéritos regulares aos conhecimentos e atitudes do público perante a ciência (European Commission, 2001; Miller et al., 2002). O primeiro destes 
inquéritos, em 1977 (feito pela Comissão Europeia), mostrou que em geral os europeus apoiavam a ciência. Apesar de muitos autores concordarem com as limitações inerentes à utilização de inquéritos na avaliação da relação do público com a ciência, estes são uma forma de comparar de forma homogénea países diferentes e anos diferentes (ver Gregory \& Miller, 1998, para uma discussão mais alargada).

No Eurobarómetro 55.2, publicado pela Comissão Europeia em 2001, Portugal é descrito como tendo baixos níveis de conhecimentos científicos; na UE os portugueses têm a média mais baixa de respostas correctas a perguntas de ciência. Portugal é o quarto país com o mais baixo índice de interesse em ciência e tecnologia. Menos de $23 \%$ da população vai a um museu, galeria de arte ou biblioteca num ano (European Commission, 2001). A admiração dos portugueses por cientistas e médicos está também abaixo da média europeia. Mais de dois terços têm uma relação distante com a ciência, tendo desenvolvido poucas estratégias de aquisição de informação científica (Firmino da Costa et al., 2002).

Esta falta de cultura científica e interesse pela ciência deverá estar relacionada, pelo menos parcialmente, com a falta de tradição de investigação científica e com os baixos níveis de escolaridade. Portugal tem sido lento no seu desenvolvimento científico e tecnológico. Só em 1967 foi esboçada uma política de ciência e tecnologia (Caraça, 1999), e o primeiro Ministério da Ciência e Tecnologia foi constituído apenas em 1994. A avaliação de projectos por equipas internacionais, tão importante na valorização de projectos competitivos e na manutenção da idoneidade dos concursos, só começou em 1993 (Henriques, 1999).

Mais de $60 \%$ dos portugueses com idade entre os 25 e os 65 anos apenas frequentou a escola primária (OCDE, 2001). Pessoas com baixo nível de escolaridade têm de facto uma relação mais distante com a ciência (Firmino da Costa et al., 2002). Nestas condições de escolaridade é difícil justificar o gasto de dinheiro em ciência, uma vez que a maior parte das pessoas, inclusive empresários e possíveis financiadores de ciência, não valorizam a investigação científica.

No entanto, algumas circunstâncias recentes deram oportunidade ao público português de se aperceber do papel da ciência na tomada de decisões políticas. A controvérsia em torno da construção da barragem no rio Foz Côa, onde foram descobertas pinturas pré-históricas (Gonçalves, 2000; 2002), o projecto COMBO - um estudo geológico envolvendo uma explosão controlada ao largo da costa do Porto (Correia, 2002) e a localização de unidades de co-incineração de resíduos industriais (Gonçalves, 2002) são referidas por investigadores como estudos de caso de controvérsias científicas com repercussões sociais, económicas e políticas. As decisões finais nestas controvérsias foram em última análise constrangidas pela opinião pública (se bem que manipuladas pelos media e grupos com interesses mais fortes).

\subsection{Abordagens à comunicação de ciência em Portugal}

A promoção da cultura científica dos cidadãos foi assumida como um programa contínuo do Estado com a criação da Agência Ciência Viva para a Cultura Científica e Tecnoló- 
gica, em 1996, passando esta a estatuto de associação em 1998. Esta agência tem sido o maior promotor de divulgação pública da ciência em Portugal (www.cienciaviva.pt), fazendo um esforço para aumentar o conhecimento e compreensão da ciência entre o público em geral e nas escolas. A Agência Ciência Viva gere oito centros interactivos, dá apoio a projectos para promover o ensino experimental em escolas e a colocação de estudantes do Ensino Secundário em laboratórios de investigação, organiza a semana nacional da Ciência e da Tecnologia e actividades relacionadas com ciência para o público em geral (por exemplo, a Astronomia no Verão).

Nos últimos anos, vários institutos de investigação e universidades em Portugal têm vindo a desenvolver as suas próprias actividades de comunicação pública da ciência, quer isoladamente, quer em colaboração com a Agência Ciência Viva: semanas de ciência, seminários, workshops para professores do ensino básico e secundário (Miller et al., 2002; www.igc.gulbenkian.pt).

As actividades de comunicação de ciência em Portugal são na sua maior parte unidireccionais - do cientista para o público - e indirectas - mediadas por jornalistas e museus. É muito raro haver discussão directa entre os cientistas e o público, sobre temas e controvérsias científicas, em formatos que possibilitem que os cientistas recebam o feedback do público e sejam informados do seu 'conhecimento situado'. Por outro lado, raramente é dado valor ao esforço de comunicação dos cientistas.

Mesmo em recentes temas controversos, em que o público teve uma influência decisiva na resolução da controvérsia - os casos das gravuras de Foz Côa e da co-incineração de resíduos industriais - o público nunca comunicou directamente com os peritos convidados pelos governantes para avaliar a situação. Os cientistas utilizaram os media (conferências de imprensa, entrevistas e artigos de opinião) como uma forma indirecta de comunicação para emitir as suas opiniões. Não foi criado um fórum de diálogo entre os vários actores (cientistas, políticos e o público), e o que se verificou foi que o público demonstrou as suas opiniões através de manifestações públicas, panfletos e slogans (Gonçalves, 2000).

\subsection{Objectivos deste estudo}

O objectivo deste estudo foi avaliar, em Portugal, as perspectivas de evolução das estratégias de comunicação de ciência: de unidireccionais e dependentes de mediadores para formas de diálogo que promovam a interacção directa de cientistas e público. As questões específicas a que este projecto pretendeu dar resposta focam no 'antes' e no 'depois' da interacção de cientistas e o público:

Antes: Será que é possível promover o diálogo entre cientistas e o público? Isto é, será que os cidadãos estarão interessados em interagir directamente com os cientistas, em vez de ler as notícias nos jornais? E estarão os cientistas disponíveis para interagir e discutir as repercussões do seu trabalho com o público?

Depois: Terá esta experiência influenciado a atitude destes cidadãos com a ciência e os cientistas? Será que os cientistas sentem que os seus pontos de vista foram assimilados e entendidos pelo público? 
De forma a responder a estas perguntas, foi planeada, organizada e avaliada uma conferência de fim-de-semana com cientistas do Instituto Gulbenkian de Ciência (IGC) e munícipes de Oeiras.

Dois objectivos estiveram subjacentes a esta conferência: por um lado, dar aos munícipes de Oeiras a oportunidade de conhecer o IGC e, por outro, discutir a investigação feita dentro e fora do Instituto, incluindo as implicações da ciência nas suas vidas diárias. Decidimos que uma conferência de fim-de-semana seria a melhor abordagem para promover este diálogo (interacção directa e bidireccional).

A conferência foi baseada no modelo dinamarquês das conferências de consenso (Grundahl, 1995; Lee, 1995; Klüver, 1995; Lee, 1995):

- o painel leigo foi seleccionado entre munícipes de Oeiras que se candidataram voluntariamente;

- aos membros do painel leigo foi dada informação sobre a história, a organização e a investigação do IGC;

- o painel leigo definiu a agenda, seleccionando os temas a serem debatidos;

- o painel dos cientistas, constituído por investigadores do IGC, foi escolhido com base nos temas escolhidos pelos cidadãos;

- os dois painéis encontraram-se durante dois dias para debater questões científicas e questões relacionadas com política de ciência e as implicações sociais e éticas da investigação biomédica;

- o painel leigo preparou o relatório de consenso, avaliando o debate e as implicações da ciência nas suas vidas.

Tanto quanto nos foi possível apurar, este foi o primeiro encontro entre cientistas e cidadãos que deu ênfase ao diálogo, no país. Esperamos que estes resultados possam ser utilizados para facilitar estratégias de comunicação via o diálogo em Portugal, de forma a promover um maior envolvimento dos portugueses em questões de ciência e tecnologia.

\section{Método}

\section{Selecção do painel leigo}

A conferência foi divulgada através de cartazes e anúncios em jornais locais ${ }^{3}$. Os cartazes foram colocados em locais estratégicos em Oeiras: em infantários, no centro de saúde, num centro de desenvolvimento infantil, na piscina municipal, nas bibliotecas municipais e num centro comercial.

\footnotetext{
${ }^{3}$ Texto do anúncio:

'Venha conhecer um Instituto de Investigação Biomédica, aqui perto, em Oeiras.

Sabia que em Oeiras, no Instituto Gulbenkian de Ciência (IGC), se procura uma vacina para a malária? E que se estuda como é que as plantas, os ratinhos e outros seres vivos adquirem a sua forma? E que se procura os genes que causam a
} 
Um anúncio de uma semana foi colocado num jornal local, de distribuição domiciliária gratuita em Oeiras. A Câmara Municipal de Oeiras inseriu, a custo nulo, um pequeno anúncio da conferência na sua revista mensal, 30 Dias, também de distribuição gratuita entre os munícipes.

Os critérios de selecção para o painel leigo foram análogos aos das conferências de consenso dinamarquesas: foram seleccionadas pessoas de idades superiores a 18 anos, sem formação científica profissional e que não representassem interesses profissionais, colectivos ou de outra natureza. Os membros do painel leigo foram seleccionados por ordem de inscrição, desde que satisfizessem os critérios de selecção. Toda a informação sobre a estrutura e organização da conferência foi fornecida através de correio electrónico e/ou pessoalmente.

\section{Informação de apoio e selecção do painel dos cientistas}

Um mês antes da conferência, cada elemento do painel leigo recebeu um documento, escrito em linguagem não-técnica, abordando a história, a estrutura e as áreas de investigação do IGC. Cada membro do painel leigo recebeu ainda uma carta expondo os objectivos e a estrutura da conferência bem como o programa para o fim-de-semana.

Cada membro do painel leigo sugeriu dois tópicos a abordar na conferência. Devido a limitações de tempo, não foi possível reunir com o painel leigo para esclarecer dúvidas técnicas e seleccionar o painel de cientistas. Deste modo, foram convidados a participar na conferência o coordenador ou investigador mais sénior dos grupos de investigação relevantes. Ao todo, foram convidados sete investigadores, todos do IGC. Aos cientistas foi explicado que deveriam apresentar a sua investigação em termos não-técnicos e responder às perguntas do painel leigo. Deveriam também ler e avaliar o relatório de consenso que o painel leigo prepararia e preencher um pequeno inquérito final.

\section{A conferência de fim-de-semana}

A conferência decorreu no fim-de-semana de 6 e 7 de Setembro de 2003, no IGC. A estrutura da conferência foi muito semelhante à de uma conferência de consenso. O fim-de-semana foi dividido em duas partes, distintas mas interligadas: no sábado, os cientistas apresentaram e debateram com o painel leigo as suas áreas específicas de investigação. Apenas os membros dos dois painéis e a organização participaram nas sessões de sábado.

\footnotetext{
diabetes e o autismo? Gostaria de conhecer os cientistas do IGC e debater com eles os benefícios, as dificuldades e possíveis cenários de futuro relacionados com a sua investigação?

Realizar-se-á, no fim-de-semana de 6 e 7 de Setembro, um debate entre os investigadores do IGC e um painel de 10 pessoas, escolhidas entre o público oeirense. O painel do público terá previamente acesso a informação detalhada sobre a investigação realizada no IGC, para depois aprofundar com os cientistas.

Caso esteja interessado(a) em participar nesta iniciativa, envie os seus contactos para:

Ana Paula Coutinho, Instituto Gulbenkian de Ciência, Rua da Quinta Grande, Apartado 14, 2781-901 Oeiras, Tel.214 407 936, Fax. 214407 970, e-mail. acoutin@igc.gulbenkian.pt, [www.igc.gulbenkian.pt]'
} 
Na manhã de domingo decorreu um debate aberto, com a participação de ambos os painéis, para debater assuntos mais abrangentes, como por exemplo, o impacto social da ciência, as políticas de ciência (em Portugal e noutros países), a ética. Este debate foi aberto a todos quantos quisessem participar, incluindo os restantes cientistas do IGC. No domingo à tarde, o painel leigo preparou e apresentou o seu relatório de consenso.

\section{O relatório de consenso}

Para a elaboração do relatório de consenso, foi sugerido ao painel leigo que abordasse os seguintes temas:

a) A conferência (Ex.: Esta conferência foi mais proveitosa do que um documentário televisivo, um livro de divulgação científica ou um artigo de jornal, no que diz respeito ao que aprendemos sobre o conteúdo e os processos da ciência?)

b) A investigação científica no IGC (Ex.: Os projectos de investigação a decorrer no IGC, que financiamos através dos nossos impostos, são relevantes para o nosso dia-a-dia?)

c) A ciência em Portugal (Ex.: Como se compara ser cientista em Portugal e noutros países? Quão bem planeada parece ser a política de ciência do país?)

d) A ciência na sociedade (Ex.: A ciência, como componente da cultura de uma nação, é apenas para as elites? Ou é para todos?)

Devido a limitações de tempo, o relatório não foi apresentado aos participantes, mas sim distribuído por todos via correio electrónico, no dia seguinte.

\section{Avaliação}

Foram distribuídos curtos inquéritos anónimos aos dois painéis, como forma de avaliar a conferência. Os inquéritos foram concebidos de modo a avaliar, por um lado, o impacto da conferência nas atitudes do público e dos cientistas face ao diálogo, e por outro, a opinião de todos os participantes sobre a organização e o decorrer da conferência.

Os membros de ambos os painéis foram questionados quanto às razões que os levaram a participar na conferência, o que esperavam obter e o que na realidade retiraram deste evento; sugeriram temas a serem abordados em conferências futuras. Em respostas de escolha múltipla, indicaram com que finalidades este tipo de conferência deveria ser implementada em Portugal. Os cientistas participantes indicaram, também através de respostas de escolha múltipla, as suas percepções em relação à forma como as suas intervenções foram assimiladas e entendidas pelos cidadãos.

Em relação à organização da conferência, ambos os painéis foram questionados quanto à duração das sessões, acessibilidade dos cientistas participantes, estrutura da conferência, contacto com a organização, entre outros itens de carácter logístico. Toda a conferência foi filmada. 


\section{Resultados}

\section{O painel leigo}

Quinze pessoas candidataram-se ao painel leigo. Este painel, com os 10 membros finais, estava constituído um mês antes da conferência. O meio de divulgação mais eficaz foi, de facto, o anúncio na revista 30 Dias: o interesse na conferência, por parte do público, aumentou com a publicação do anúncio e cinco dos oito membros do painel souberam da conferência graças àquele.

Assim, o painel leigo era constituído por oito pessoas: cinco mulheres e três homens. Das 10 pessoas seleccionadas, duas acabaram por não participar na conferência, por razões familiares.

Um finalista do Ensino Secundário, de 18 anos de idade, era o membro mais novo do painel leigo. Este painel incluía ainda duas estudantes universitárias (de Química Aplicada e Engenharia Biológica), com 19 e 21 anos, uma funcionária pública licenciada em Psicologia Social, de 43 anos de idade, uma professora do Ensino Secundário com 51 anos, uma doméstica com 42 anos, um geólogo reformado, com 76 anos, e um engenheiro químico reformado, de 65 anos de idade. Todos vivem em Oeiras e arredores.

$\mathrm{Na}$ altura da selecção para o painel leigo, os participantes indicaram as razões que os levavam a querer participar na conferência. Os participantes mais novos esperavam saber mais sobre os projectos de investigação no IGC e estabelecer contactos com possíveis orientadores científicos. Um dos participantes queria aprender mais sobre a genética do autismo e diabetes. Os mais velhos queriam 'conhecer o que se faz no IGC em termos de investigação básica e aplicada, em particular no campo da genética e biomedicina, tentando consegui-lo em linguagem descodificada', numa perspectiva 'social e de cidadania', reflectir nas 'implicações filosóficas da engenharia genética', e ainda nas 'repercussões sociais e práticas dos projectos de investigação'.

Estas razões, apontadas antes da conferência, foram confirmadas nos inquéritos pós-conferência. Entre as razões apontadas para a sua participação, seis dos oito membros do painel escolheram 'para conhecer o IGC', cinco escolheram 'para abordar temas científicos específicos' e metade indicaram 'para conhecer cientistas' e 'para estabelecer contactos para o futuro'. Outras razões indicadas foram 'para conhecer a estrutura científica em Portugal' e 'para conhecer os cientistas e compreender um pouco mais a sua vida'.

Todos os membros do painel leigo leram o texto de apoio sobre o IGC, fornecido antes da conferência; a maior parte dos membros do painel complementou esta informação recorrendo à página de Internet do IGC (cinco dos oito) e a outras publicações (cinco dos oito).

O painel leigo propôs oito temas científicos para debate, que foram incluídos no programa da conferência: genética do autismo, biologia do desenvolvimento, auto-imunidade, vírus e hospedeiros, bioinformática, divisão celular e apóptose, neoangiogénese e cancro. Outros temas, mais abrangentes, também propostos foram: a noção de 'tempo' em Biologia, as dificuldades em fazer ciência em Portugal, e bioética e as questões éticas na investigação em Biologia. 


\section{O painel dos cientistas}

Cinco coordenadores de grupo, uma investigadora de pós-doutoramento e uma médica investigadora aceitaram o convite para participar na conferência. O painel dos cientistas era constituído por quatro homens e três mulheres, com idades compreendidas entre os 30 e 45 anos.

A maioria dos cientistas aceitou participar na conferência para promover o IGC (cinco dos sete) e porque foram convidados (cinco dos sete). Três dos sete cientistas revelaram que participaram 'para promover o estatuto do cientista na sociedade'.

Entre as outras razões para participar estavam 'conhecer a opinião do público de Oeiras sobre os cientistas', 'ganhar experiência na comunicação da ciência com o público em geral', '[avaliar] o possível impacto/choque do nosso trabalho', 'conhecer a disponibilidade de contribuição financeira do cidadão em relação à ciência em Portugal', 'contacto mais informal com outros colegas' e 'mostrar o investigador como pessoa normal'.

\section{A conferência de fim-de-semana}

\section{Dia 1 - Sábado}

Os membros do painel leigo interromperam regularmente, com perguntas, as sete sessões que decorreram durante o dia, o que possibilitou um diálogo constante entre os dois painéis.

O painel leigo considerou os cientistas ou muito claros (quatro dos oito) ou claros (quatro dos oito), e ou muito acessíveis (quatro dos oito) ou acessíveis. Esta opinião foi partilhada pelo painel dos cientistas: os cientistas participantes foram claros (seis dos seis) e acessíveis (cinco dos cinco que responderam à pergunta).

\section{Dia 2 - Domingo}

\section{Debate aberto - Domingo de manhã}

Apenas três cientistas do IGC e três munícipes assistiram ao debate, apesar de este ser aberto ao público e todos os investigadores e trabalhadores do IGC.

O painel leigo determinou a agenda deste debate e deu início à discussão. Alguns dos temas abordados no domingo de manhã foram:

- áreas de investigação biomédica que não tinham sido abordadas no dia anterior. Desta conversa inicial surgiu um debate sobre a razão de ser de certos projectos de investigação (motivações históricas, económicas e sociais) e a motivação dos cientistas. Um dos cientistas disse que estudava 'o ciclo celular porque é giro... Sei que se pode relacionar com cancro, mas eu gosto porque para mim é belo observar e tentar compreender como é que as células se dividem';

- a investigação fundamental versus a investigação aplicada;

- as políticas de ciência em Portugal; comparações entre os recursos materiais disponíveis aos cientistas em Portugal e noutros países. Os participantes reflectiram sobre se seria mais vantajoso para Portugal, sendo um país pequeno e com recursos limitados, apostar nas áreas de investigação aparentemente mais relevantes para a economia nacional, ou, alternativamente, apostar nos cientistas de excelência, independentemente da área de estudo; 
- a função do governo no sistema de financiamento da ciência portuguesa e a necessidade de se encontrarem fontes alternativas de financiamento - desde as grandes empresas ao cidadão individual. Foram feitas comparações com as instituições sem fins lucrativos no Reino Unido que apoiam a investigação científica. Todos concordaram que é necessário maior sensibilização para e maior compreensão da ciência e que iniciativas como aquela em que estavam a participar poderiam dar uma forte contribuição;

- educação de ciência. Muitos membros do painel leigo lamentaram que os três jovens do painel sejam uma excepção entre os seus pares, que, dum modo geral, não gostam e rejeitam o estudo da ciência. Os cientistas foram encorajados a serem pro-activos, indo às escolas para 'transmitir esta imagem de jovens a fazer coisas estimulantes para o futuro do país'.

Para a maior parte dos membros do painel leigo, o debate foi útil (sete dos oito); um ficou indiferente ao debate. Cinco dos seis cientistas que participaram consideraram o debate útil; o outro cientista considerou-o indiferente.

\section{A visita aos laboratórios do IGC - Domingo à tarde}

A visita aos laboratórios, realizada a seguir ao debate, não tinha sido incluída no programa, mas acabou por ser um ponto alto do fim-de-semana. Um dos membros do painel leigo sugeriu, no inquérito final, que 'uma visita mais longa aos laboratórios fosse incorporada na conferência'.

\section{O relatório de consenso}

O painel leigo reuniu durante aproximadamente uma hora e meia e elaborou o relatório abaixo transcrito. Os membros de painel consideraram que o tempo de elaboração do relatório foi suficiente (cinco de cinco que responderam). Todos declararam ter sido útil a elaboração do relatório, cujo texto se transcreve:

O contacto directo com os investigadores é mais enriquecedor e mais vital que a simples leitura de um artigo científico tanto a nível de conteúdo como a nível de processo.

É inquestionável que a utilização dos impostos dos contribuintes em investigação pura e aplicada em biologia e engenharia genética traz benefícios para a vida de todos nós.

Parece-nos que ser cientista em Portugal significa ter menos recursos, menos oportunidades e estabilidade, essenciais à investigação.

Relativamente à Ciência em Portugal, foi consensual que é necessário organizar, planificar, suscitar investimentos e criar uma cultura científica, capazes de gerar sinergias entre a comunidade científica e os cidadãos.

Vivemos em plena era da Ciência! Como da cultura científica advêm vantagens para toda a sociedade, a actividade científica tem necessária e inequivocamente de ser uma preocupação colectiva. Pensamos que seria vantajoso estimular o 
diálogo dos cientistas com a sociedade através de uma divulgação mais ampla do seu trabalho. Efectivamente consideramos que a comunidade científica tem a responsabilidade social de passar a sua mensagem. É também importante a criação de uma cultura de diálogo interdisciplinar entre os cientistas.

A Tabela 1 resume a avaliação do relatório de consenso feita pelo painel dos cientistas. De um modo geral, os cientistas ficaram satisfeitos com o relatório. Salientamos que os cientistas foram de opinião de que o painel leigo assimilou correctamente os factos que lhe foram transmitidos e concordaram com o painel leigo em como o debate foi mais enriquecedor do que a leitura de um livro ou artigo de divulgação científica.

Tabela 1 - A opinião dos cientistas sobre o relatório de consenso

\begin{tabular}{|l|c|}
\hline \multicolumn{1}{|c|}{ Painel cientistas $(\mathbf{N}=6)$} & $\begin{array}{c}\text { Média } \pm \text { desvio } \\
\text {-padrão }\end{array}$ \\
\hline $\begin{array}{l}\text { O painel assimilou correctamente os factos que lhe foram } \\
\text { transmitidos }\end{array}$ & $2 \pm 0.7$ \\
\hline Sinto que as minhas intervenções foram bem entendidas & $2 \pm 0.8$ \\
\hline Partilho das opiniões apresentadas pelo painel relativamente ao debate & $2 \pm 0.8$ \\
\hline $\begin{array}{l}\text { Partilho das opiniões apresentadas pelo painel relativamente } \\
\text { à investigação no IGC }\end{array}$ & $3 \pm 0.98$ \\
\hline $\begin{array}{l}\text { Partilho das opiniões apresentadas pelo painel relativamente } \\
\text { à ciência em Portugal }\end{array}$ & $2 \pm 0.7$ \\
\hline $\begin{array}{l}\text { Partilho das opiniões apresentadas pelo painel relativamente } \\
\text { à ciência como forma de cultura }\end{array}$ & $2 \pm 0.98$ \\
\hline
\end{tabular}

Escala: 1 - concordo plenamente; 2 - concordo; 3 - não concordo nem discordo; 4 - discordo; 5 - discordo em absoluto.

\section{Avaliação global da conferência}

A conferência foi globalmente avaliada como Boa/Muito Boa. Três (dos oito) membros do painel leigo consideraram a conferência excelente; dois (dos sete) cientistas participantes consideraram-na razoável.

Quando questionados sobre o que tinham gostado menos durante a conferência, e de que forma poderia ser melhorada, vários cientistas e um ou dois membros do painel leigo referiram a falta de público a assistir. Muitos cientistas comentaram que a iniciativa tinha sido demasiado longa e que um número demasiado elevado de temas foi abordado. Estas últimas observações não foram feitas por nenhum dos membros do painel leigo. 
No que respeita ao que de melhor a conferência ofereceu, os cientistas apreciaram o interesse e a compreensão que o público demonstrou: 'comprovar que há 'nãocientistas' que efectivamente querem compreender o que é [a ciência] e o que aqui acontece'. Alguns cientistas ficaram satisfeitos por terem tido oportunidade de 'poder esclarecer dúvidas e transmitir informação', e ainda de 'poder apresentar o prazer de fazer ciência (...) e de poder responder directamente às perguntas do público'.

O painel leigo gostou do espírito de abertura dos cientistas, do modo como apresentaram e debateram os temas e do ambiente informal. Uma das pessoas no painel leigo escreveu que o que mais apreciou foi 'acreditar que existem jovens portugueses (...) a lutarem para manter a investigação viva em Portugal'. Outra pessoa apreciou o 'consenso na apresentação do relatório'.

Todos os membros do painel leigo participariam noutra conferência deste género. Quatro dos cientistas também participariam noutra conferência, os outros três talvez participassem.

A Tabela 2 resume as respostas do painel leigo à pergunta concebida para avaliar o efeito da conferência sobre a atitude dos participantes face à ciência (tornou-se mais positiva e aumentaram os conhecimentos científicos), face aos cientistas (melhorou) e face à comunicação directa entre cientistas e o público (é mais produtiva). Os valores (de desvio-padrão) das perguntas sobre a opinião em relação aos cientistas e a atenção a notícias sobre o IGC, revelam que este painel continha pessoas já com uma opinião favorável aos cientistas e já conhecedores e atentos ao IGC.

Tabela 2 - Atitudes do painel leigo após a conferência

\begin{tabular}{|l|c|}
\hline \multicolumn{1}{|c|}{ Painel leigo (N=7) } & $\begin{array}{c}\text { Média } \pm \text { desvio } \\
\text { - padrão }\end{array}$ \\
\hline A minha atitude perante a ciência é mais positiva & $1 \pm 0.5$ \\
\hline Tenho melhor opinião sobre os cientistas & $2 \pm 1.2$ \\
\hline Os meus conhecimentos científicos aumentaram & $2 \pm 0.8$ \\
\hline $\begin{array}{l}\text { Tirei mais deste debate do que tiraria de um livro/artigo } \\
\text { de jornal/documentário de televisão }\end{array}$ & $2 \pm 0.8$ \\
\hline Estarei mais atento(a) a notícias sobre o IGC & $1 \pm 1.0$ \\
\hline Fiquei mais sensibilizado(a) para notícias de ciência em geral & $2 \pm 0.5$ \\
\hline
\end{tabular}

Escala: 1 - concordo plenamente; 2 - concordo; 3 - não concordo nem discordo; 4 - discordo; 5 - discordo em absoluto.

Os dois painéis concordaram sobre a implementação na sociedade de conferências do género desta: estas conferências devem ser empregues, inclusivamente para avaliar assuntos do âmbito da ciência e da tecnologia e para contribuir para definir as políticas de ciência do país (Tabela 3 ). 
Tabela 3 - Situações em que este formato de conferência deveria ser empregue, de acordo com cada um dos painéis

\begin{tabular}{|l|c|c|}
\hline & $\begin{array}{c}\text { Painel cientistas } \\
\text { Média } \pm \\
\text { desvio-padrão }\end{array}$ & $\begin{array}{c}\text { Painel leigo } \\
\text { Média } \pm \\
\text { desvio-padrão }\end{array}$ \\
\hline Promover as imagens dos institutos de investigação & $2 \pm 0.5$ & $2 \pm 1.2$ \\
\hline $\begin{array}{l}\text { Aumentar os conhecimentos científicos do público } \\
\text { em geral }\end{array}$ & $1 \pm 0.4$ & $2 \pm 0.8$ \\
\hline $\begin{array}{l}\text { Contribuir para a avaliação pública de determinada } \\
\text { área científico-tecnológica }\end{array}$ & $2 \pm 0.99$ & $3 \pm 1.1$ \\
\hline $\begin{array}{l}\text { Contribuir para a elaboração da política de ciência } \\
\text { do país }\end{array}$ & $2 \pm 1.1$ & $2 \pm 0.8$ \\
\hline Não deveria ser implementado & & \\
\hline
\end{tabular}

Escala: 1 - concordo plenamente; 2 - concordo; 3 - não concordo nem discordo; 4 - discordo; 5 - discordo em absoluto.

\section{Consequências da conferência}

Estas foram as consequências imediatas da conferência de fim-de-semana:

1. Um artigo de meia página num jornal diário nacional de grande tiragem, o Diário de Notícias (Naves, 8 Setembro 2003: 23).

2. Um convite para 'repetir alguns dos aspectos do fim-de-semana' numa tertúlia de reformados oeirenses, em Outubro de 2003. Foram abordados vários temas, incluindo políticas de ciência, gestão institucional e temas científicos específicos.

3. O debate 'Dialogar Ciência', na Biblioteca Municipal de Oeiras, a convite da Câmara Municipal de Oeiras, com um painel de investigadores do IGC (dia 24 de Janeiro de 2004). O painel era constituído por cientistas em diferentes fases das suas carreiras (desde estudantes de licenciatura até um dos directores-adjuntos do IGC). Cerca de 50 pessoas assistiram ao debate. Foram debatidos temas científicos específicos (como, por exemplo, clonagem e doenças genéticas) e temas mais abrangentes, nomeadamente a rotina diária de um cientista, políticas de ciência, as perspectivas de carreira em Portugal para os cientistas jovens, como promover a cultura científica. Tal como na conferência de fim-de-semana, todos os cientistas presentes foram encorajados a serem pro-activos na divulgação de ciência, deslocando-se às escolas e a outras instituições locais. Na sequência deste debate, os investigadores do IGC foram convidados a visitar o centro da Associação Portuguesa de Paralisia Cerebral (APPC) de Oeiras para exporem a actividade dos cientistas do IGC aos utentes daquele centro.

\section{Discussão}

A conferência de fim-de-semana descrita neste estudo permitiu-nos avaliar a atitude de um grupo de cientistas e do público português ao diálogo. Apesar das limitações 
deste estudo, o facto de ter sido possível realizar esta conferência e as suas consequências imediatas sugerem que ambos os grupos - cientistas e público - têm interesse em desenvolver esta forma de comunicação directa e bidireccional, e são beneficiados pela experiência.

\subsection{Porquê promover o diálogo entre cientistas e o público em Portugal?}

De acordo com os dados do Eurobarómetro 55.2, Portugal apresenta um atraso em relação a muitos outros países europeus, no que diz respeito ao conhecimento e interesse do público pela ciência (Miller et al., 2002). No relatório de benchmarking da promoção da compreensão pública da ciência, encomendado pela Comissão Europeia em $2002^{4}$, foi proposto um novo indicador para o clima de promoção da compreensão pública da ciência em cada país, baseado no quociente Conhecimento/Interesse (K/I) (Miller et al., 2002). O valor de K/I para Portugal indica que as actividades realizadas não satisfazem completamente as necessidades do público, o que sugere uma necessidade de aumentar o interesse pela ciência $(\mathrm{K} / \mathrm{I}=0.96$, um pouco abaixo do valor standard de 1.00).

Acontecimentos recentes em Portugal (as gravuras de Foz Côa, o projecto COMBO e a crise da BSE) têm atirado a ciência para o domínio público, revelando o quanto certas decisões político-administrativas estão dependentes de conhecimentos científicos. É de esperar que o interesse do público pela ciência aumente, na sequência destas controvérsias, à medida que os cidadãos se aperceberem das implicações da ciência nas suas vidas diárias. É também muito provável que a imagem da ciência como uma actividade neutra, não problemática e constituída por um conhecimento único - a imagem apresentada pelo 'modelo do défice cognitivo' (Thomas, 1997; Gregory \& Miller, 1998) - seja posta em causa. Este fenómeno de desilusão em relação à ciência tem tido consequências bem visíveis nos níveis de interesse em certos países europeus, nomeadamente na Alemanha (de 1991 a 2002 o interesse pela ciência baixou 29\%; Miller et al., 2002). Pelo contrário, na Dinamarca, onde os fóruns de diálogo entre cientistas e o público têm sido implementados e estimulados, e onde os cidadãos são envolvidos nas decisões sobre assuntos científico-tecnológicos, o interesse pela ciência aumentou 32\% entre 1992 e 2001 (Miller et al., 2002).

Desde as crises registadas em torno das gravuras de Foz Côa, do projecto COMBO e da co-incineração (Correia, 2002; Castro \& Lima, 2002; Gonçalves, 2002), parece estar a desenvolver-se em Portugal uma nova cultura política, na qual as decisões político-administrativas estão ligadas ao saber científico (Gonçalves, 2002). Há que acautelar, no entanto, que esta nova tendência não induza o aparecimento de uma forma de 'ciência de advogacia' (advocacy science), em que os cientistas (e o conhecimento científico) são recrutados pelos grupos participantes com o objectivo de enfraquecer os argumentos dos opositores. Numa situação de advocacy science são menosprezados os contextos socioeconómicos, legais, culturais e institucionais em que o

\footnotetext{
${ }^{4}$ Report from the Expert Group Benchmarking the Promotion of RTD Culture and Public Understanding of Science.
} 
processo de decisão decorre, e a forma como estes contextos afectam a utilização do conhecimento científico, que é utilizado parcimoniosamente. Por outro lado, nascem sentimentos de frustração e de logro, por parte do público, quando os cientistas a que os decisores recorrem se revelam tantas vezes incapazes de fornecer certezas e verdades absolutas (o que também facilita a utilização parcimoniosa do seu conhecimento) (Horlick-Jones \& De Marchi, 1995; Gonçalves, 2002). O diálogo entre cientistas e público contraria estas tendências: por um lado revela como o conhecimento científico in the making - aquele que é de facto relevante para muitas das decisões de base científica (vejam-se as decisões de gestão de risco na questão da doença de Creutzfeld-Jacobs, por exemplo) - avança precisamente sobre as dúvidas e as incertezas científicas que o caracterizam. Por outro lado, o diálogo possibilita que sejam incorporados outros tipos de conhecimento nos processos de tomada de decisão, que reflictam os contextos sociais e económicos envolvidos.

A experiência e os casos de sucesso de outros países, no domínio da comunicação de ciência e do envolvimento do público com a ciência, deverão servir de base para o esforço da promoção da cultura científica em Portugal. Neste sentido, a conferência de fim-de-semana entre os cientistas do IGC e o público de Oeiras teve como objectivo contornar os obstáculos de comunicação entre os dois grupos, criando um espaço onde o público pudesse 'confrontar' os cientistas directamente, abordando os temas científico-tecnológicos que mais preocupam os cidadãos.

\subsection{Avaliando as questões do 'Antes' e do 'Depois'}

A falta de audiência durante a conferência foi a principal crítica dos participantes. Atribuímos o facto de apenas uma pequeníssima parte das pessoas convidadas (entre cientistas e munícipes de Oeiras) terem comparecido à novidade da iniciativa. De facto, no debate 'Dialogar Ciência', que resultou directamente da conferência, a audiência foi significativamente maior (cerca de 50 pessoas). Este debate foi também melhor e mais largamente divulgado pela Câmara Municipal de Oeiras, o que terá contribuído para a maior participação do público.

Mesmo 50 participantes representam uma pequena porção da população total, o que revela existir ainda um longo caminho a percorrer para envolver o público (e também os cientistas) em diálogo. O maior desafio será o de envolver aqueles para quem tais iniciativas passam ao lado, por não terem ainda a percepção da relevância da ciência nas suas vidas.

A maioria dos cientistas participou na conferência de fim-de-semana com o intuito de promover o IGC e porque foi convidado. Alguns afirmaram, explicitamente, que esperavam, através da conferência, 'ganhar experiência em comunicar com o público', e 'conhecer a disponibilidade de contribuição financeira do cidadão em relação à ciência em Portugal'. Estas afirmações indicam que estes cientistas comunicam com o público por razões de interesse próprio e reforça as conclusões de estudos anteriores das estratégias de comunicação utilizadas por cientistas portugueses (Jesuíno \& Diego, 2002). No seu estudo, que envolveu um grupo de investigadores de diferentes áreas, 
Jesuíno e Diego concluíram que os cientistas portugueses recorrem à comunicação com o público como uma forma de aumentarem a visibilidade dos sucessos e feitos da ciência e da tecnologia. Esta motivação faz lembrar os princípios subjacentes ao 'modelo do défice cognitivo', segundo o qual as iniciativas de compreensão pública da ciência constituem uma maneira de conseguir transmitir a mensagem dos cientistas. Esta mensagem tem, por vezes, como finalidade atrair mais estudantes para as disciplinas de ciência, ou até, numa posição extrema, é uma tentativa de obter financiamentos alternativos aos do Estado. Muitos cientistas comunicam a sua ciência num esforço de aumentar a cultura científica da população. Em qualquer dos casos, pressupõe-se sempre um público ignorante da ciência, que precisa de ser educado e convencido da beleza e virtudes da ciência.

As razões que os cientistas apontaram para participarem na conferência estão na mesma linha que as conclusões do workshop 'Comunicar Ciência', descritas no artigo de Bettencourt-Dias, Coutinho \& Araújo, neste número. Os projectos de comunicação de ciência que os participantes neste workshop conceberam como exercício eram todos dirigidos à promoção da ciência e até ao envolvimento do público nas maravilhas da ciência; nenhum dos projectos foi concebido em torno do diálogo entre cientistas e o público-alvo, que permitisse a participação do público na ciência.

Apesar de tudo, quando questionados sobre as formas como esta conferência poderia ser utilizada no futuro, a maior parte dos cientistas participantes apontou a avaliação de assuntos científico-tecnológicos e até a definição de políticas de ciência como aplicações desejáveis. Uma vez que estas opiniões foram expressas a seguir à conferência, somos levados a sugerir que a conferência alterou as suas opiniões iniciais, as quais se podem atribuir à novidade do conceito da participação do público em ciência, em Portugal.

Ambos os painéis sugeriram temas para conferências futuras entre cientistas e o público. O painel leigo sugeriu os seguintes: os últimos desenvolvimentos tecnológicos, a engenharia genética, a investigação com células estaminais, o sistema imune, a cultura científica dos jovens, ética e limites da biologia da medula óssea e da investigação utilizando embriões e o stress celular. $\mathrm{O}$ painel dos cientistas propôs o tema das políticas de ciência em Portugal, a ciência como meio de desenvolvimento, a 'nova genética', a história da ciência e as suas implicações sociais.

Os tópicos acima descritos abarcam áreas científicas específicas, mas também temas mais abrangentes. Curiosamente, estes últimos apareceram como o enfoque do painel dos cientistas, o que poderá revelar um afastamento do 'modelo do défice cognitivo'. De acordo com este modelo, numa tentativa de reduzir o défice de conhecimento do público, a informação que é transmitida é constituída maioritariamente pelos conceitos e factos da ciência (Miller et al., 2002), em prejuízo dos valores e dos processos da ciência. As sugestões de temas para futuras conferências foram feitas depois desta, pelo que somos, mais uma vez, levados a sugerir que a conferência alterou a atitude dos cientistas na forma de comunicação com o público.

Ao permitir que o painel leigo determinasse os temas a debater e ainda que conduzisse o debate aberto, o seu 'conhecimento situado' manifestou-se. De facto, os mem- 
bros deste painel estavam constantemente a tentar integrar tudo o que ouviam com saberes previamente adquiridos, quer nas suas vidas profissionais, quer pessoais. Um dos membros, por exemplo, referia-se constantemente à sua doença; interpretava e avaliava a investigação que lhe era descrita, bem como as repercussões para si e para a sua vida familiar, em termos dos conhecimentos acumulados ao longo de anos de tratamentos e visitas a médicos.

O painel leigo estava, claramente, mais interessado no 'processo' da ciência do que no 'conteúdo' da ciência (Claxton, 1997). Apesar da quantidade de informação que lhes foi transmitida, sobre teorias, conceitos e termos científicos, o painel leigo focou-se naquilo a que Durant chama 'a ciência como uma instituição' (Gregory \& Miller, 1998): a formação e o treino de cientistas, o sistema de revisão pelos pares (peer review), os protocolos seguidos numa investigação, as motivações e os valores da ciência (e dos cientistas). No seu relatório, abordaram algumas destas questões e aconselharam os cientistas a serem pro-activos na sua comunicação com o público.

Todos os membros do painel leigo participariam noutra conferência deste género. Os cientistas mostraram-se menos entusiasmados em participar noutra iniciativa. Vários cientistas comentaram que um fim-de-semana é tempo demais para 'perder' neste tipo de evento. Estas opiniões poderão indicar que os cientistas consideram que a comunicação de ciência, sendo pouco reconhecida, continua a ser uma actividade secundária quando comparada com aquilo que consideram ser a sua função principal - levar a cabo as suas investigações. Esta opinião é partilhada por cientistas noutros países, mesmo naqueles onde a comunicação de ciência está mais bem inserida no sistema científico, como o Reino Unido, por exemplo (Pringle, 1997).

No seu relatório, de 2002, uma das recomendações feitas pelo grupo de trabalho de benchmarking da promoção da compreensão pública da ciência é de que as actividades de divulgação e promoção da ciência, realizadas pelos cientistas, sejam um dos factores determinantes da progressão na carreira científica (Miller et al., 2002). Parece-nos muito provável que medidas desta natureza aumentem a vontade e a disponibilidade dos cientistas para participarem em iniciativas de comunciação de ciência em geral, e em fóruns de diálogo em particular.

\section{Conclusões e perspectivas para o futuro}

Conferências públicas, debates de uma tarde ou uma manhã e dias abertos, no âmbito da comunicação de ciência, existem já em Portugal. A conferência de fim-de-semana entre os cientistas do IGC e o público de Oeiras aqui descrita difere daquelas iniciativas em vários aspectos:

- os cientistas e os membros do público passaram um fim-de-semana inteiro juntos, o que permitiu várias rondas de debate;

- o painel leigo definiu a agenda e, na medida do possível, conduziu os acontecimentos;

- o painel leigo teve oportunidade de se preparar detalhadamente para a conferência, tendo recebido material de apoio de antemão; 
- chegou-se a uma opinião de consenso no final da conferência: o relatório elaborado pelo painel leigo continha uma única opinião consensual e não as opiniões de cada participante;

- os cientistas puderam avaliar e dar a sua opinião sobre o relatório de consenso.

Em conjunto, as características acima referidas possibilitaram o diálogo entre os participantes. Esta conferência foi totalmente inovadora em Portugal e permitiu que cientistas e o público se encontrassem e se conhecessem numa perspectiva diferente. O sucesso desta experiência-piloto sugere que a comunicação bidireccional é possível e agrada a ambos os grupos envolvidos: cientistas e o público.

Apesar de esta conferência ter envolvido apenas investigadores da área da biomedicina, parece-nos uma iniciativa facilmente transponível para outras áreas científicas. Poder-se-ão debater temas específicos, em relação aos quais existam repercussões sociais e éticas perceptíveis para o público. Alguns exemplos de tais temas seriam: os riscos ambientais de novos sistemas de tratamento de resíduos, os testes genéticos e a política científico-tecnológica do país.

A divulgação destas conferências requer um planeamento cuidado, de modo a assegurar uma participação pública eficaz - a base do sucesso de tais iniciativas. O nosso estudo sugere que a taxa de sucesso é significativamente maior quando há participação da autarquia local - repare-se que a pequena nota na revista da Câmara Municipal de Oeiras acabou por ser a melhor forma de divulgação da conferência.

As conferências de consenso, em que nos baseámos ao conceber esta conferência de fim-de-semana, são, por um lado, uma forma de avaliação pública de aplicações tecnológicas e, por outro lado, uma experiência em democracia, uma vez que implicam uma consulta directa aos cidadãos em vez de aos seus representantes eleitos (Durant, 1995). Não prevemos que as conferências de consenso, ou qualquer das outras formas de participação do público na ciência, sejam empregues em Portugal a este nível, a curto prazo, pois somos um país dominado por instituições de democracia representativa fortemente implantadas no sistema político-administrativo.

Actualmente, os debates públicos em torno de assuntos científico-tecnológicos em Portugal baseiam-se num sistema de entrega voluntária das opiniões de todos os cidadãos, via a Internet ou por outros meios tradicionais. A participação dos cidadãos nestes debates é geralmente pobre (veja-se o recente debate sobre a utilização de embriões humanos em investigação: Serrão, 2003). Gostaríamos de propor que os fóruns de diálogo, incluindo as conferências de consenso, venham a substituir este modelo não estruturado de debates públicos em Portugal. As opiniões de consenso dos cidadãos participantes poderiam servir como ponto de referência para o debate institucional, esse sim com carácter decisório.

A outro nível, as conferências de consenso são também uma forma de diálogo entre o público e os cientistas e um excelente espaço para a promoção da ciência e para o envolvimento do público em assuntos científico-tecnológicos. Os membros do painel leigo afirmaram que retiraram mais desta conferência do que de um livro de divulgação 
científica, um artigo no jornal ou até um documentário televisivo; ficaram com opiniões mais positivas sobre os cientistas; aumentaram os seus conhecimentos científicos e estariam mais atentos a notícias sobre ciência depois da conferência. É a este nível que valerá a pena que cientistas, políticos e comunicadores de ciência invistam o seu tempo e esforço, de modo a promover o envolvimento do público português com a ciência.

\section{Agradecimentos}

A conferência de fim-de-semana foi realizada com o apoio financeiro do Instituto Gulbenkian de Ciência. Gostaríamos de agradecer à Câmara Municipal de Oeiras todo o apoio na divulgação da conferência. Agradecemos ainda a todos no Instituto Gulbenkian de Ciência que tornaram a conferência possível, em particular, António Coutinho, Greta Martins e Jorge Costa.

\section{Referências}

Ávila, P. \& Castro, P. (2002) 'Compreender a Ciência: O Inquérito à Cultura Científica dos Portugueses' in M. E. Gonçalves (org.) Os Portugueses e a Ciência, Lisboa: Dom Quixote, pp. 287-320.

Bodmer, W. (1985) The Public Understanding of Science: Report of an Ad Hoc Group Endorsed by the Council of the Royal Society, London: Royal Society.

Caraça, J. (1999) 'A Prática de Política de Ciência e de Tecnologia em Portugal' in Caraça, J. M. (org.) O Futuro Tecnológico: Perspectivas para a Inovação em Portugal, Oeiras: Celta Editora.

Castro, P. \& Lima, M. L. (2002) 'Discursos sobre a Ciência num Debate Ambiental' in Gonçalves, M. E. (org.) Os Portugueses e a Ciência, Lisboa: Dom Quixote, pp. 115-156.

Claxton, G. (1997) 'Science of the Times: a 2020 Vision of Education' in Levinson, R. and Thomas, J. (eds.) Science Today: Problem or Crisis?, London: Routledge, pp. 71-86.

Correia, M. (2002) 'O Verso e o Reverso das Representações da Ciência. As Abordagens do Projecto COMBO que Passaram na Televisão’ in Gonçalves, M. E. (org.) Os Portugueses e a Ciência, Lisboa: Dom Quixote, pp. 79-114.

Durant, J. (1995) 'An Experiment in Democracy' in Joss, S. \& Durant, J. (eds) Public Participation in Science: The Role of Consensus Conferences in Europe, London: Science Museum, pp. 75-80.

European Commission Directorate General for Research (2001) Eurobarometer 55.2 Europeans, Science and Technology, Brussels: European Commission.

Farmelo, G. (1997) 'From Big Bang to Damp Squib?' In Levinson, R. \& Thomas, J. (eds) Science Today: Problem or Crisis?, London: Routledge, pp. 175-191.

Firmino da Costa, A., Ávila, P. \& Mateus, S. (2002) Públicos da Ciência em Portugal, Lisboa: Gradiva.

Gonçalves, M. E. (2000) 'Ciência, Política e Participação: O Caso de Foz Côa' in Gonçalves, M. E. (org.) Cultura Científica e Participação Pública, Oeiras: Celta Editora, pp. 201-230.

Gonçalves, M. E. (2002) 'Imagens Públicas da Ciência e Confiança nas Instituições: Os Casos de Foz Côa e da Co-incineração’ in Gonçalves, M. E. (org.) Os Portugueses e a Ciência, Lisboa: Dom Quixote, pp. 157-197.

Gregory, J. \& Miller, S. (1998) 'Popularization, Public Understanding and the Public Sphere' in Science in Public: Communication, Culture and Credibility, New York: Plenum Press, pp. 81-103.

Gründhal, J. (1995) 'The Danish Consensus Conference Model' in Joss, S. \& Durant, J. (eds) Public Participation in Science: The Role of Consensus Conferences in Europe, London: Science Museum, pp. 31-40. 
Hamstra, A. (1995) 'The Role of the Public in Instruments of Constructive Technology Assessment' in Joss, S. \& Durant, J. (eds) Public Participation in Science: The Role of Consensus Conferences in Europe, London: Science Museum, pp. 53-66.

Henriques, L. (1999) 'Sistemas Consultivos e Estratégias de Selecção de Projectos de I\&D: Portugal, os Últimos 20 Anos’ in Godinho, M. M. e Caraça, J. M. (orgs.) O Futuro Tecnológico: Perspectivas para a Inovação em Portugal, Oeiras: Celta Editora.

Horlick-Jones, T. \& De Marchi, B. (1995) 'The crisis of scientific expertise in fin de siècle Europe', Science and Public Policy, 22(3):139-145.

House of Lords Select Committee on Science and Technology (2000) Science and Society, London: House of Lords .

Irwin, A. (1995) Citizen Science, London: Routledge.

Jesuíno, J. C. \& Diego, C. (2002) 'Estratégias de Comunicação da Ciência' in Gonçalves, M. E. (ed.) Os Portugueses e a Ciência, Lisboa: Dom Quixote, pp. 235-286.

Jorgensen, T. (1995) 'Consensus Conferences in the Health Care Sector' in Joss, S. \& Durant, J. (eds.) Public Participation in Science: The Role of Consensus Conferences in Europe, London: Science Museum, pp. 17-30.

Joss, S. \& Durant, J. (1995) 'Introduction' in Joss, S. \& Durant, J. (eds) Public Participation in Science: The Role of Consensus Conferences in Europe, London: Science Museum, pp. 9-13.

Klüver, L. (1995) 'Consensus Conferences at the Danish Board of Technology' in Joss, S. \& Durant, J. (eds.) Public Participation in Science: The Role of Consensus Conferences in Europe, London: Science Museum, pp. 41-52.

Lee, G. (1995) 'A Consensus Conference from the Point of View of a Lay-panel Member' in Joss, S. \& Durant, J. (eds.) Public Participation in Science: The Role of Consensus Conferences in Europe, London: Science Museum, pp. 81-88.

Miller, S. C., Caro, P., Koulaidis, V., De Semir, V., Staveloz, W. \& Vargas, R. (2002) Report from the Expert group Benchmarking the Promotion of RTD Culture and Public Understanding of Science, Brussels: European Commission.

Naves, F. (2003) 'Cidadãos e Cientistas num Frente a Frente Informal e Produtivo', Diário de Notícias, 8 Setembro, p. 23.

Organisation for Economic Co-operation and Development (2003) Education at a Glance, Paris: OECD. Pringle, S. (1997) 'Sharing Science' in Levinson, R. \& Thomas, J. (eds.) Science Today: Problem or Crisis?, London: Routledge, pp. 206-223.

Serrão, D. (2003) Livro Branco sobre o Uso de Embriões Humanos em Investigação Científica, Lisboa: Ministério da Ciência e do Ensino Superior.

Thomas, J. (1997) 'Informed Ambivalence: Changing Attitudes to the Public Understanding of Science' in Levinson, R. \& Thomas, J. (eds) Science Today: Problem or Crisis?, London: Routledge, pp. 163174.

Wynne, B. (2001) 'Creating Public Alienation: Expert Cultures of Risk and Ethics on GMOs', Science as a Culture, 10: 445-481. 